\title{
Numerical Simulation and Optimization of Fine- Blanking Process for Copper Alloy Sheet
}

\section{Chun-Chih Kuo}

National Kaohsiung University of Science and Technology

Kuo-Wang Liu

National Kaohsiung University of Science and Technology

Tse-Chang Li

National Kaohsiung University of Science and Technology

Dai-You Wu

National Kaohsiung University of Science and Technology

Bor-Tsuen Lin ( $\nabla$ bt_lin@nkust.edu.tw )

National Kaohsiung University of Science and Technology

\section{Research Article}

Keywords: fine-blanking, finite element analysis, multicriteria optimization, Pareto-optimal

Posted Date: March 11th, 2021

DOI: https://doi.org/10.21203/rs.3.rs-251652/v1

License: (c) (i) This work is licensed under a Creative Commons Attribution 4.0 International License. Read Full License

Version of Record: A version of this preprint was published at The International Journal of Advanced Manufacturing Technology on November 10th, 2021. See the published version at https://doi.org/10.1007/s00170-021-08225-6. 


\title{
Numerical simulation and optimization of fine-blanking process for copper alloy sheet
}

Chun-Chih Kuo ${ }^{\mathrm{a}, \mathrm{b}}$, Kuo-Wang Liu ${ }^{\mathrm{a}}$, Tse-Chang Li ${ }^{\mathrm{b}}$, Dai-You Wu ${ }^{\mathrm{a}}$, Bor-Tsuen Lin ${ }^{\mathrm{a}, \mathrm{b},{ }^{*}}$

${ }^{\text {a }}$ Department of Mechatronics Engineering, National Kaohsiung University of Science and Technology (First Campus), Kaohsiung, Taiwan.

${ }^{\mathrm{b}}$ Metal Product Development Technology R\&D Center, National Kaohsiung University of Science and Technology (First Campus), Kaohsiung, Taiwan.

* Corresponding author
E-mail: bt_lin@nkust.edu.tw

\begin{abstract}
When the fine-blanking process is used, secondary grinding or processing can be omitted because the shear surface of fine-blanking parts can achieve almost zero fracture zone requirements. Fine-blanking has the advantages of high precision and high production efficiency. It was originally used on watch parts, but with increasingly refined technology, it has been widely applied in computers, consumer electronics, communication products, and vehicle parts. The primary objective of the fine-blanking process is to reduce the fracture zone depth and die roll zone width. This study used a $2.5 \mathrm{~mm}$ thick central processing unit (CPU) thermal heat spreader as an example. Finite element analysis software was employed to simulate and optimize the main eight process parameters that affect the fracture zone depth and die roll zone width after fineblanking: the V-ring shape angle, V-ring height of the blank holder, V-ring height of the cavity, V-ring position, blank holder force, counter punch force, die clearance, and
\end{abstract}


blanking velocity. Simulation analysis was conducted using the L18 $\left(2^{1} \times 3^{7}\right)$ Taguchi orthogonal array experimental combination. The simulation results of the fracture zone depth and die roll zone width were optimized and analyzed as quality objectives using Taguchi's smaller-the-better design. The analysis results revealed that with fracture zone depth as the quality objective, $0.164 \mathrm{~mm}$ was the optimal value, and counter punch force made the largest contribution of $25.89 \%$. In addition, with die roll zone width as the quality objective, the optimal value was $1.274 \mathrm{~mm}$, and V-ring height of the cavity made the largest contribution of $29.45 \%$. Subsequently, this study selected fracture zone depth and die roll zone width as multi-criteria quality objectives and used the robust multi-criteria optimal approach and Pareto-optimal solutions to perform multi-criteria optimization analysis. The results revealed the optimal fracture zone depth and die roll zone width were $0.239 \mathrm{~mm}$ and $1.288 \mathrm{~mm}$, respectively. Finally, the experimental results verified that the fracture zone depth was $0.230 \mathrm{~mm}$ and die roll zone width was $1.205 \mathrm{~mm}$. The findings met the industry's fraction zone depth standard (below $12 \%$ of blank thickness) and achieved a smaller die roll zone width.

Keywords: fine-blanking, finite element analysis, multicriteria optimization, Paretooptimal

\section{Introduction}

The fine-blanking process is a stamping technology that separates a product from sheet metal, which is also an efficient and economical shearing process. In recent years, fine-blanking has been used in fine mechanics, automobiles, electronics, and aviation. The fine-blanking process is usually accompanied by poor shearing quality when the geometric shape of a product is complex [1]. The die roll is often used as a crucial indicator of quality in fine-blanking. Luo et al. [2] discussed the difference between the 
die roll zone and central zone of the blanking velocity. They assumed that each die roll is determined by an imaginary circle that defines the ratio of usable and unusable volumes, and that inserting a sliding block can protect parts without a V-ring from shear failure. In addition, utilizing the unusable area to control and insert the sliding block into the combination can reduce the die roll phenomenon. Finite element analysis (FEA) and experimental results revealed that the die roll size could be reduced by $70 \%$. Krobath et al. [3] investigated the load cycle of the punch in the fine-blanking process and the unload cycle of the punch withdrawing after punching. Their study focused on the tensile load and local stress ratio of the punch and analyzed the smallest defects on the surface of the WC-Co hardened steel punch under fatigue load conditions to quantitatively estimate and calculate the critical value of fatigue crack growth. The punch material and the maximum allowable defect size and position were obtained through FEA, and the durability of the punch could be extended by altering its shape. Zheng et al. [4] used wear testing to explore the edge passivation effect on a microstructured sheet metal surface during the fine-blanking and extrusion process. FEA was used to calculate the correlation between stress distribution and interface contact behavior. They also analyzed the effect of material fluidity of the punched edge on the punching geometry and wear profile of the extrusion stroke. The results indicated that reducing the length of the straight line and arc caused a large material flow distance on the punched edge. Moreover, the wear was more severe on the punch with round edges than on the one with straight edges. The V-shaped ring was an essential structure in the fine-blanking process, improving the surface quality of blank shearing. Its main functions were fixing the blank to avoid bending and stretching during the shearing process, suppressing the displacement and deformation caused by the lateral shearing force in the blanking process, and increasing the three-axis compressive stress and material rigidity of the deformation area for reducing the die roll size. Mao et al. [5] 
proposed that the geometric parameters of discontinuous pressure points included the pressure point diameter, fillet radius, distribution, position, and height. They used an experimental design and analysis of variance (ANOVA) to optimize and analyze the effect of discontinuous pressure points on the geometric parameters of the shear plane. The optimized geometric parameters were used in spur gear manufacturing. The experimental results indicated that the discontinuous pressure point of the blank holder could improve the shear plane quality and could also be used to reduce the cost of fineblanking. Due to the increased production speed and use of high strength steel sheet, factors such as wear, crack formation, and damage in blanking tools will reduce their lifetimes. Claus et al. [6] proposed evaluating the effect of blank heat treatment and surface finishing on friction characteristics and lifetimes. The experimental results revealed that the heat treatment method of the punch, surface roughness of the punch, selection of punch materials, and use of lubricants have great effects on the life and wear behavior of the punch. Furthermore, Liu et al. [7] applied FEA to the fine-blanking process of a triangular tooth gear and discussed the effect of die structure parameters on the die roll size. They optimized the die structure through reducing the die roll size, extending the die life, and preventing the occurrence of cross-sectional cracks. Their experimental results can be used to obtain the relationship between the blank holder force magnitude and die roll size in different fine-blanking processes. Compared with the conventional fine-blanking process, the magnitude of the blank holder force had little effect on the die roll size. Zheng et al. [8] found that changes in product materials and shapes as well as the design evolution of the blank holder can affect product quality. In general, the die roll size can be used as a crucial indicator for evaluating product quality and digital technology. Therefore, the researchers determined that current trends and prospects of the fine-blanking industry and its applications can be applied in the research and development of electric cars. 
In the fine-blanking process, the directions of blanking and shearing are related to the anisotropic mechanical properties of the metal blank and orientation of crystallites. According to observations of the side microstructure in fine-blanking products, the blanking and shearing directions can be divided into the deformation, shear, and failure zones. The current fine-blanking process tends to reduce the size of the deformation zone and improve the initiation and growth of microcracks in the failure zone. The critical damage value of the metal blank depends on the stress state of the material during the fine-blanking process. Therefore, it is crucial to accurately grasp the elastoplastic behavior of large strain and the critical damage criterion. To date, literature has mostly discussed the application of FEA combined with a damage model to simulate the damage behavior of the shear plane [9] and die design to control the quality of the shear surface [10]. Wang [11] used a slotted ring to replace the conventional V-ring in the fine-blanking process. The addition of the slotted ring ensures uniform back pressure in the cavity, and this pressure can be achieved through hydraulic, pneumatic, or spring force. The research results indicated that the shear surface roughness of the blank was between 0.03 to $0.08 \mu \mathrm{m}$, and the diameter tolerance was between IT2 and IT4 (ISO 286). This production method can completely replace the conventional V-ring, and the quality of its shear surface exceeds that obtained through conventional fineblanking. Zhao et al. [12] conducted microstructure observation to determine the fracture failure mode in the shear zone of the DP600 steel plate fine-blanking process. A self-adjustable triaxial stress model was adopted to simulate the damage behavior of the shear zone. In addition, the study evaluated the plastic strain, stress distribution, load-displacement response, damage evolution, and crack growth behavior for experimental verification. Wang et al. [13] used a scanning electron microscope to observe the microstructure of the shear surface of an ultra-thin blank and employed the Abaqus software package to simulate a three-dimensional fine-blanking process on the 
basis of effective plastic strain and the Gurson-Tvergaard-Needleman shear correction model. The experimental results indicated that cracks first occurred on the symmetrical surface of the punch edge, and grew along the maximum damage path to the free surface. The size effect accelerated the stress level and damage evolution. In addition, Barik et al. [14] used Simulation software ABAQUS to change the forming and geometric parameters to perform FEA on the fine-blanking process of aluminum alloy AA6082T6. An experimental design method was employed to optimize the fine-blanking process and the effect of forming and geometric parameters on burr formation on the metal blank after fine-blanking. This method can improve product quality and reduce production costs. In summary, increasing the fillet radius and clearance on the punch side can increase the burr height, and the evolution pattern of the shear strain field in the shear zone revealed the probability of cracks on the punch side. In the production of high-precision parts, the ratio of the shear surface to the cutting surface must be considered, and the optimal tools and punching conditions must be selected within the cost limit to obtain a high-quality shear surface. Tanaka et al. [15] used FEA to calculate the ratio of the shear plane to the fracture surface and evaluated the ductile fracture criteria of Oyane, Cockcroft, and Latham using four punching methods. The results indicated that various types of shear surface will be affected by the clearance between the punch and die, clamping method of the blank, and selection of ductile fracture criteria.

A servo die cushion is a forming method that can self-adjust the blank holder force in the press equipment with high speed and stability. However, in the case of complex product shapes or high-strength material applications, the general forming process which cannot be achieved by conventional mechanical or hydraulic presses can be overcome by combining a servo press with a servo die cushion. The servo press exhibits an adjustable curvilinear motion on the upper press, and the servo die cushion can adjust 
the blank holder force arbitrarily. Therefore, blanking processes that cannot be formed by conventional machinery or hydraulic presses can be achieved according to the forming conditions required by different blanking processes. At present, literature on servo die cushions involve servomotor-related technology and metal forming industry applications [16], the use of high-frequency impulsive vibration to improve forming quality and efficiency [17], and the use of FEA and remeshing to define the standard in blanking formability analysis [18]. Kim et al. [19] proposed computer-aided engineering analysis combined with an experimental design method to confirm the technical methods required by the servo press in the forging process. The experimental design method could effectively optimize the pressure distribution required for the forming process of continuously variable pulleys and spur gears. The experimental results revealed that the pressure distribution required to completely fill the tooth profile could be obtained through the tooth profile forming process, which could reduce the excess forming load during the gear-tooth forming process. Olguner and Bozdana [20] proposed a finite element model for a dual-phase steel plate to evaluate the reduction of steel plate thickness and the change of forming load in the pulse pressure distribution curve during the drawing process. They also changed the frequency and amplitude of the pulse pressure to perform elastoplastic FEA with DEFORM-3D. The results suggested that a pulse frequency of $20 \mathrm{~Hz}$ and pulse amplitude of $0.125 \mathrm{~mm}$ reduced the forming force by $7 \%$. Compared with pulseless forming, a pulse frequency of 20 $\mathrm{Hz}$ reduced the thickness from $27.8 \%$ to $23.9 \%$. A servo press in conjunction with a servo die cushion can precisely control the movement of the upper press and blank holder force during the blanking process, thus reducing the forming difficulty. Fallahiarezoodar et al. [21] applied a servo die cushion to the drawing and formation of the U-channel of Al 5182-O. A blank was stretched and bent when it was near the rounded corner of the cavity; it was not bent when it passed the rounded corner. The 
reversing load generated by the bending process produced a residual stress distribution in the direction of the blank section. The application of the servo die cushion reduced the residual stress distribution and wall springback. The results revealed that the postextension effect significantly reduced the residual stress distribution and wall springback. Moreover, Esmaeilpour et al. [22] used a servo press and die cushion to form three aluminum alloy sheets in a cross shape. The uniaxial tensile test was used to construct the anisotropic properties of the aluminum alloy sheet, and the Argus system was used to measure the strain of the draw forming. The formed part was cut in two different directions using a water-jet machine to measure the thickness change after forming. The study used Yld2000-2D and Hill's 48 yield function for numerical simulation analysis and comparison with experimental values. The experimental results demonstrated that the Yld2000-2D's yield function was suitable for modeling crossshaped aluminum alloy parts.

The most common problem encountered in the process of blanking products is how to reduce costs and improve quality, which is generally related to the selection of process parameters, die geometry, and blank material. In the industry, the trial and error method is often used for tryout process, but this relies on rich experience and involves huge costs, and discovering solutions for nonlinear problems could be difficult. In the blanking process, the fracture zone and die roll zone are the surface features that must be produced on the shear surface. Both zones will affect the size and performance of the finished product and even cause problems such as secondary processing. Therefore, the ability to control the size of the fracture and die roll zones in the blanking process is crucial.

The present study used a thickness $2.5 \mathrm{~mm}$ C1100 copper plate central processing unit (CPU) thermal heat spreader as an example to investigate the key process parameters of fine-blanking, including the effects of blanking velocity, V-ring height of 
the blank holder, V-ring height of the cavity, V-ring shape angle, V-ring position, blank holder force, counter punch force, and die clearance on the fracture zone depth and die roll zone width. First, this study performed a tensile test simulation analysis on the C1100 copper plate and imported the test parameters into the DEFORM software package to obtain the critical damage value of the material. Subsequently, the Taguchi orthogonal array L18 $\left(2^{1} \times 3^{7}\right)$ experiment combination was used to conduct a fineblanking simulation analysis. Moreover, the fracture zone depth and die roll zone width were set as the quality objectives for process optimization analysis, where the Taguchi method's smaller-the-better quality design was used to identify the correlation between process parameters and quality objectives through ANOVA. Furthermore, the optimal combination of process parameters was obtained through the robust multicriteria optimal approach and Pareto-optimal solutions. Finally, experiments were performed to verify the accuracy of the results of the optimal process parameter combination analysis.

\section{Experimental equipment and die}

The greatest differences between a fine-blanking die and a general blanking die are the die clearance, V-ring, and counter punch in the cavity. The die clearance is approximately $0.5-1.5 \%$ of the blank thickness, and the shear surface of the finished product occupies more than $80 \%$ of the shear surface. V-rings are commonly added to the blanks and cavities to increase the precompression internal stress of the blanks for reducing the generation of tensile stress, thereby improving the plasticity of the material, slowing the generation of the fracture zone, and preventing blanks in the waste area from flowing into the finished product area. The function of the counter punch in the cavity is to press the material on the back during shearing, mainly to increase the precompression internal stress inside it to increase its plasticity and restrain the material 
to ensure greater flatness.

The fine-blanking process is divided into three stages, as depicted in Fig. 1. Before blanking, the blank is clamped and fixed by the blank holder and the cavity, the punch descends, and the counter punch contacts the blank simultaneously. During blanking, the counter punch exerts ejection force to clamp the material and perform the blanking while pressing the punch into the cavity. After blanking, the counter punch continues to support the material and stops at the end position after the punch is pressed into the cavity and exceeds the thickness of the blank. After the punch rises and is demolded, the blank is pushed out of the cavity to complete the fine-blanking process. The aforementioned actions of the counter punch can be completed by a servo die cushion.

To meet practical requirements, a fine-blanking die was designed with the CPU thermal heat spreader parts as an example. The die structure is presented in Fig. 2. The upper die system included an upper die set, upper block, upper die base, nitrogen gas spring, punch, punch fix plate, punch back plate, blank holder plate, holder back plate, and guide post. The lower die system included a lower die set, lower die base, counter punch, servo cushion block, cavity insert, cavity plate, cavity back plate, and bushing. First, the blank was placed on the cavity plate for positioning. During blanking, the blank was clamped by the blank holder through the force exerted by the nitrogen gas spring. The blank was pressed into the cavity simultaneously by the punch, and the counter punch in the cavity was pressed against the blank by the servo die cushion to generate an ejection force. In cooperation with the servo die cushion, the die was sheared from top to bottom. Upon completion, the upper die system opened, the finished blank was ejected from the cavity by the counter punch, and the blank could be removed. The thickness $2.5 \mathrm{~mm} \mathrm{C1100} \mathrm{copper} \mathrm{plate} \mathrm{was} 99.9 \%$ copper. The blank was $60 \mathrm{~mm}$ long $\times 70 \mathrm{~mm}$ wide. In addition, this study used a servo press (SEYI SD1200, Shieh Yih Machinery Industry, Taiwan) for the fine-blanking experiments, as 
depicted in Fig. 3. The forming tonnage of the servo press was 200 ton, the maximum output tonnage of the servo die cushion was 15 ton, and the maximum forming speed was 50 strokes/min. The forming motion curves can be set according to different forming requirements, and the servo die cushion can be matched with said motion to directly control the stroke and speed.

\section{Tensile test}

In the simulation analysis, a tensile test had to be conducted to obtain the mechanical properties of the copper alloy $\mathrm{C} 1100$. The size of the tensile test piece conformed to ASTM E8M specifications, and the size and test piece are presented in Fig. 4. This study used a $100 \mathrm{kN}$ MTS 810 dynamic tensile testing machine to measure the mechanical properties of the copper alloy $\mathrm{C} 1100$. The tensile speed of the tensile test was $1 \mathrm{~mm} / \mathrm{min}$. The tensile test could only obtain the load-elongation curve, whereas the true stress and strain were based on the actual cross-sectional area and length of the test piece under the load. Therefore, the load-elongation curve of the material had to be converted into a true stress-true strain curve. Fig. 5 depicts the true stress-true strain curve of the copper alloy $\mathrm{C} 1100$. The obtained mechanical properties of the material were incorporated into DEFORM 2D and DEFORM 3D software for simulation analysis.

To present a blank fracture situation during shearing, ductile fracture criteria must be used as the basis for the blank fracture during the simulation analysis. This study used the normalized Cockcroft-Latham fracture criterion as the critical damage value in simulation analysis. To obtain the critical damage value of the copper alloy C1100, the thickness of the material at the necking fracture of the test piece was measured after the tensile test was completed, and then the material tensile test simulation analysis was performed. The analysis model of the tensile test is illustrated in Fig. 6. This study 
simulated the thickness at the necking fracture to obtain the normalized CockcroftLatham critical damage value required by the material, as demonstrated in Fig. 7. The critical damage value of copper alloy in the C1100 tensile test analysis simulation was 2.04. Finally, said value was imported into DEFORM 2D and DEFORM 3D for simulation analysis. When the mesh attained the critical damage value, it was deleted. This approach was used to present the material fracture situation.

\section{Optimization of fine-blanking parameters}

This study employed the fracture zone depth and die roll zone width of the CPU thermal heat spreader as the quality objectives, as illustrated in Fig. 8. The fracture zone depth was required to be as small as possible to obtain satisfactory size tolerance and avoid secondary processing problems. In addition, to avoid the reduction of the contact area of the finished product, which leads to a poor heat dissipation effect, the die roll zone width had to be as small as possible.

This study adopted Taguchi methods as the experimental design. These are systematic and effective methods that greatly reduce the number of experiments and can determine the optimal design parameter values that meet performance and cost requirements. The first step was to determine the key parameters. The most crucial fineblanking process parameters that affect the fracture zone depth and die roll zone width in fine-blanking include the blanking velocity, V-ring height of the blank holder, V-ring height of the cavity, V-ring shape angle, V-ring position, blank holder force, counter punch force, and die clearance, which are illustrated in Fig. 9. In this experiment, the L18 $\left(2^{1} \times 3^{7}\right)$ orthogonal array was adopted. The process parameters and levels are explained as follows:

(1) The height and position of the V-ring can affect the length of the shear zone. The precompression internal stress of the shear zone increases with the V-ring height, 
which increases the length of the shear zone. When the V-ring position is closer to the punch, the length of the shear zone increases, and the width and length of the die roll zone decrease [23]. Therefore, this study set three levels for each parameter: the heights of the V-ring on the blank holder were $0.1,0.2$, and $0.3 \mathrm{~mm}$, heights of the V-ring on the cavity were $0.15,0.30$, and $0.45 \mathrm{~mm}$, positions of the V-ring were $0.15,0.20$, and $0.25 \mathrm{~mm}$, and V-ring shape angles were 60,90 , and $120^{\circ}$.

(2) When the die clearance increases, the shear zone of the material is widely diffused, causing the blank to enter the fracture zone early during shearing, which in turn affects the depth of the shear zone [24]. In fine-blanking, the die clearance was approximately $0.5-1.5 \%$ of the blank thickness $(2.5 \mathrm{~mm})$, and the die clearances were $0.0125,0.025$, and $0.0375 \mathrm{~mm}$.

(3) Increases in blank holder force and counter punch force will cause the material flow to rotate in the shear zone, thus increasing the precompression internal stress to prevent cracks [25]. The blank holder forces selected were 100, 140, and $180 \mathrm{KN}$, while the counter punch forces were 80,115 , and $150 \mathrm{KN}$.

(4) Blanking velocity is strongly related to increasing production speed, which were 2 $\mathrm{mm} / \mathrm{s}$ and $10 \mathrm{~mm} / \mathrm{s}$.

The aforementioned experimental parameters and levels (as presented in Table 1) were configured for the L18 $\left(2^{1} \times 3^{7}\right)$ Taguchi orthogonal array, as presented in Table 2 .

This study used DEFORM 2D to simulate the fine-blanking process and optimize the process parameters. The analysis model included the punch, blank holder, blank, counter punch, and cavity, as depicted in Fig. 10 (a). The CATIA software package was used to draw the geometry of the experimental die and import it into DEFORM-2D. The blank material was set as an elastoplastic body, while the punch, blank holder, cavity, and counter punch were set as a rigid body. Approximately 10,000 meshes were established on the blank, and local mesh refinement was performed in the shear and 
deformation zones. The size of the generated mesh was approximately $0.04 \times 0.04 \mathrm{~mm}^{2}$, and the friction coefficient was set to 0.12 according to [25]. To prevent excessive deformation of the mesh or it penetrating into the die, the mesh was automatically refined when the interference was greater than $0.01 \mathrm{~mm}$ to prevent calculation divergence. The simulation process used an isotropic elastic-plastic material model to define the deformation behavior of the blank, the true stress-true strain curve obtained by the tensile test, and the critical damage value obtained by the tensile test simulation analysis, which were imported into the FEA software. The simulation was of the blanking process from the punch to the end position after the punch contacted the blank, as depicted in Fig. 10 (b).

To effectively determine the die roll zone width and fracture zone depth, the contour line of the shear cross-section by FEA results were converted into IGS files and imported into CATIA software. During the blanking process, the shear cross-section of the blank was divided into the fracture, shear, and die roll zones from top to bottom, as presented in Fig. 11. Therefore, the contour line of the shear cross-section above and below the shear zone was defined as the fracture zone and the die roll zone, respectively. The shearing surface of the blank was close to the cavity wall during the blanking process, and shearing zone was a vertical line $\overline{a b}$. The vertical distance from point a to point $\mathrm{c}$ (top side of the blank) is the fracture zone depth $\overline{a c}$. The vertical distance from point $\mathrm{b}$ to point $\mathrm{d}$ (bottom side of the blank) is the die roll zone depth $\overline{b d}$. The horizontal distance from point e (end point of the horizontal line on the bottom side) to the vertical line $\overline{a b}$ is die roll zone width.

\section{Results and discussion}

\subsection{Single-objective optimization}

The Taguchi methods used the signal-to-noise $(\mathrm{S} / \mathrm{N})$ ratio for quality measurement. 
Through process parameter design experiments, the predictable part was used as the signal and the unpredictable part was used as noise. In addition, the predictable part was maximized and the unpredictable part was minimized to improve quality and reduce variation. In this study, the fracture zone depth and die roll zone width were selected as the quality objectives, and the fracture zone depth on the shear surface was reduced to improve the dimensional accuracy of the finished product. Furthermore, the die roll zone width was reduced to improve the heat dissipation efficiency. Therefore, both quality objectives adopted the smaller-the-better design. The $\mathrm{S} / \mathrm{N}$ ratio calculation method was as follows:

$$
S / N=-10 \log _{10}(M S D)=-10 \log _{10}\left(\frac{1}{n} \sum_{i=1}^{n} y_{i}^{2}\right)
$$

The analysis data and $\mathrm{S} / \mathrm{N}$ ratio are listed in Table 3, and an $\mathrm{S} / \mathrm{N}$ ratio response graph using Taguchi methods is presented in Fig. 12. The optimal combination of process parameters with fracture zone depth as the quality objective consisted of a blanking velocity of $2 \mathrm{~mm} / \mathrm{s}$, blank holder V-ring height of $0.2 \mathrm{~mm}$, cavity V-ring height of $0.45 \mathrm{~mm}$, V-ring position of $2 \mathrm{~mm}$, blank holder force of $180,000 \mathrm{~N}$, counter punch force of $150,000 \mathrm{~N}$, die clearance of $0.0125 \mathrm{~mm}$, and V-ring shape angle of $60^{\circ}$. This combination was the fifth group of experiments in L18, and the fracture zone depth was $0.164 \mathrm{~mm}$. Moreover, ANOVA was performed to calculate the degree of effect of each process parameter on the quality objectives. The results of quality variance analysis of the fracture zone depth are presented in Table 4, where counter punch force can be observed to have made the highest contribution (25.89\%) to the fracture zone depth. This was followed by the V-ring position (21.02\%), cavity V-ring height (19.03\%), die clearance (11.13\%), blank holder V-ring height (10.05\%), blank holder force (6.72\%), 
V-ring shape angle (3.41\%), and lastly blanking velocity $(0.25 \%)$.

When the die roll zone width was the quality objective, measurements were performed using the smaller-the-better design. According to the analysis results of the L18 orthogonal array (Table 5) and the $\mathrm{S} / \mathrm{N}$ ratio response graph (Fig. 13), the optimized parameter combination for die roll zone width was a blanking velocity of $10 \mathrm{~mm} / \mathrm{s}$, blank holder V-ring height of $0.2 \mathrm{~mm}$, cavity V-ring height of $0.45 \mathrm{~mm}$, V-ring position of $1.5 \mathrm{~mm}$, blank holder force of $140,000 \mathrm{~N}$, counter punch force of $150,000 \mathrm{~N}$, die clearance of $0.0125 \mathrm{~mm}$, and V-ring shape angle of $90^{\circ}$. The die roll zone width was $1.274 \mathrm{~mm}$, which was a reduction of $0.034 \mathrm{~mm}$ from the smallest die roll zone width in L18. The quality ANOVA results for the die roll zone width are presented in Table 6, where the V-ring height of the cavity $(29.45 \%)$ can be observed to have made the highest contribution. This was followed by the V-ring shape angle $(28.88 \%)$, die clearance (25.54\%), V-ring height of the blank holder (4.70\%), V-ring position (3.91\%), blanking velocity $(3.69 \%)$, counter punch force $(2.40 \%)$, and blank holder force $(1.13 \%)$.

\subsection{Multicriteria optimization}

According to a comparison of optimized combination results between the fracture zone depth and die roll zone width (Table 7), both zones were in conflict with some parameter levels, making it difficult to select the optimal parameter level for multiple objectives. Therefore, this study adopted the method of Kunjur and Krishnamurty to extend the Taguchi method and developed a robust multicriteria optimal approach [26] to discuss the level combination of multiobjective optimal process parameters.

(1) Parameter A (blank velocity): The contribution of blank velocity was $0.25 \%$ and $3.69 \%$ to the fraction zone depth and die roll zone width, respectively. These contributions were both low. However, an F-test on the die roll zone 
width was $\mathrm{F}_{\mathrm{A}}>\mathrm{F}_{0.05}(2,2)=19$, making blank velocity a significant parameter to the die roll zone width. Therefore, $10 \mathrm{~mm} / \mathrm{s}$ was selected as the optimal level with high production efficiency.

(2) Parameter B (V-ring height of the blank): This parameter's contribution to the fraction zone depth and die roll zone width was $10.50 \%$ and $4.70 \%$, respectively, which were determined to be low contributions to both zones. However, once this parameter was optimized in both objectives through singleobjective optimization, $0.2 \mathrm{~mm}$ was selected as the optimal level.

(3) Parameter C (V-ring height of the cavity): This parameter's contribution to the fraction zone depth and die roll zone width was $19.03 \%$ and $29.45 \%$, respectively, which were determined to be medium contributions to both zones. Nevertheless, the F-test result of the die roll zone width was $F_{C}>F_{0.05}(2,2)=$ 19. Thus, this parameter was determined to be significant to the die roll zone width, and $0.45 \mathrm{~mm}$ was selected as the optimal level.

(4) Parameter D (V-ring position): This parameter's contribution to the fracture zone depth was a moderate $21.02 \%$, and its contribution to the die roll zone width was low at $3.91 \%$. Therefore, it was determined to be a secondary parameter, and the original design interval was used as the adjustment interval.

(5) Parameter E (blank holder force): This parameter's contribution was $6.72 \%$ and $1.13 \%$ to the fraction zone depth and die roll zone width, respectively. The parameter was nonsignificant because both contributions were low and the Ftest result of the two was less than $\mathrm{F}_{0.05}(2,2)=19$. To ensure the blank had greater precompression internal stress, $180,000 \mathrm{~N}$ was selected as the optimal level.

(6) Parameter F (counter punch force): This parameter's contribution to the fracture zone depth was a moderate $25.89 \%$, and its contribution to the die roll 
zone width was low at $2.40 \%$. This parameter was determined to be a secondary parameter, and the original design interval was used as the adjustment interval.

(7) Parameter G (die clearance): This parameter's contribution was $11.13 \%$ and $25.54 \%$ to the fraction zone depth and die roll zone width, respectively. In addition, the F-test result of the die roll zone width was $\mathrm{F}_{\mathrm{G}}>\mathrm{F}_{0.05}(2,2)=19$, which demonstrated that this parameter was significant to the die roll zone width. Therefore, $0.0125 \mathrm{~mm}$ was selected as the optimal level.

(8) Parameter H (V-ring shape angle): This parameter's contribution was 3.41\% and $28.88 \%$ to the fraction zone depth and die roll zone width, respectively. Moreover, the F-test result of the die roll zone width was $F_{H}>F_{0.05}(2,2)=19$; therefore, the parameter was significant to die roll zone width, and $90^{\circ}$ was selected as the optimal level.

The process parameter range of the robust multicriteria optimal approach is as follows:

$\mathrm{A}=10 \mathrm{~mm} / \mathrm{sec}, \mathrm{B}=0.2 \mathrm{~mm}, \mathrm{C}=0.45 \mathrm{~mm}, 1.5 \mathrm{~mm} \leq \mathrm{D} \leq 2.5 \mathrm{~mm}, \mathrm{E}=180,000 \mathrm{~N}$, $80,000 \mathrm{~mm} \leq \mathrm{F} \leq 150,000 \mathrm{~mm}, \mathrm{G}=0.0125 \mathrm{~mm}, \mathrm{H}=90^{\circ}$.

According to the aforementioned design range, a set of Pareto-optimal solutions was generated for a simulation analysis [26]. Table 8 presents the Pareto optimality simulation results. In compliance with the industry standard, the fraction zone depth had to be less than $12 \%(0.3 \mathrm{~mm})$ of the blank thickness, which is the main consideration, and the die roll zone width is the secondary consideration. The second set of simulation results, presented in Table 8 and Fig. 14, obtained the smallest fraction zone depth. It ranked second in die roll zone width, which was only $0.008 \mathrm{~mm}$ away from the first. 
Therefore, the following parameters were selected as the robust multicriteria optimal process parameter combination: blanking velocity of $10 \mathrm{~mm} / \mathrm{s}$, blank holder V-ring height of $0.2 \mathrm{~mm}$, cavity V-ring height of $0.45 \mathrm{~mm}$, V-ring position of $2 \mathrm{~mm}$, blank holder force of $180,000 \mathrm{~N}$, counter punch force of $115,000 \mathrm{~N}$, die clearance of 0.0125 $\mathrm{mm}$, and V-ring shape angle of $90^{\circ}$.

\subsection{Experiment and verification}

To confirm the accuracy of the FEA software, experiments were conducted to verify the analysis results. The robust multicriteria optimal process parameter combination was used to conduct a forming experiment, and the measurement results of the fracture zone depth and die roll zone width were compared with the analysis results. Fig.15 depicts the finished product and measurement position of the fineblanking experiment. A comparison between the experimental and analytical results is presented in Table 9. In terms of fraction zone depth, the analytical value of the model was $0.009 \mathrm{~mm}$ larger than the experimental value, which was considered consistent. In terms of die roll zone width, although the FEA set the blank as an isotropic material, the blank became an anisotropic material after being processed by rolling. Therefore, when the blank crystallite rolling direction was perpendicular to the die cavity edge (A zone in Fig. 15), the die roll zone width of $1.109 \mathrm{~mm}$ outperformed the simulation result. In addition, when the blank crystallite rolling direction was parallel to the die cavity edge (B zone in Fig. 15), the die roll zone width was $1.205 \mathrm{~mm}$, which was less than the simulation result of $1.288 \mathrm{~mm}$, but both values were close. The shear cross-section of the product was measured using a three-dimensional laser scanning confocal microscope (VK-X100 K, Keyence Inc., Japan) to scan the surface topography of the fine-blanking shear surface (A Zone). The results are presented in Fig. 16. 


\section{Conclusion}

In this study, the fine-blanking of a CPU thermal heat spreader was used as an example to optimize the process parameters. To reduce the fracture zone depth and die roll zone width, single-objective optimization of the fine-blanking parameters was performed. Subsequently, the effect of the fine-blanking parameters on each quality objective for robust multicriteria optimal design was analyzed, and the optimal design results were verified with experiments. The research results can be summarized as follows:

(1) Taking the fracture zone depth as the quality objective, the optimal combination of process parameters was a blanking velocity of $2 \mathrm{~mm} / \mathrm{s}$, blank holder V-ring height of $0.2 \mathrm{~mm}$, cavity V-ring height of $0.45 \mathrm{~mm}$, V-ring position of $2 \mathrm{~mm}$, blank holder force of $180,000 \mathrm{~N}$, counter punch force of $150,000 \mathrm{~N}$, die clearance of $0.0125 \mathrm{~mm}$, and V-ring shape angle of $60^{\circ}$. The fracture zone depth was $0.164 \mathrm{~mm}$. According to the ANOVA results, the effect of the counter punch force was the largest with a contribution of $25.89 \%$. The fracture zone depth decreased as the counter punch force tonnage became higher.

(2) Taking die roll zone width as the quality objective, the optimal combination of process parameters was a blanking velocity of $10 \mathrm{~mm} / \mathrm{s}$, blank holder V-ring height of $0.2 \mathrm{~mm}$, cavity V-ring height of $0.45 \mathrm{~mm}$, V-ring position of $1.5 \mathrm{~mm}$, blank holder force of $140,000 \mathrm{~N}$, counter punch force of $150,000 \mathrm{~N}$, die clearance of $0.0125 \mathrm{~mm}$, and V-ring shape angle of $90^{\circ}$. The die roll zone width was $1.274 \mathrm{~mm}$. In addition, the ANOVA results indicated that the effect of the V-ring height of the cavity was the largest with a contribution of $29.45 \%$. Increasing the V-ring height of the cavity will reduce the die roll zone width accordingly.

(3) This study used a robust multicriteria optimal approach and Pareto-optimal solutions, and set the fracture zone depth as the main objective and the die roll zone 
width as the secondary objective. The combination of multicriteria optimal process parameters was a blanking velocity of $10 \mathrm{~mm} / \mathrm{s}$, blank holder V-ring height of 0.2 $\mathrm{mm}$, cavity V-ring height of $0.45 \mathrm{~mm}$, V-ring position of $2 \mathrm{~mm}$, blank holder force of $180,000 \mathrm{~N}$, counter punch force of $115,000 \mathrm{~N}$, die clearance of $0.0125 \mathrm{~mm}$, and V-ring shape angle of $90^{\circ}$. This combination not only met the industry's standard for fracture zone depth but could also obtain a smaller die roll zone width.

(4) The comparison between the experimental and analysis results revealed that the difference in fracture zone depth was as small as $0.009 \mathrm{~mm}$. In terms of die roll zone width, due to the blank grain rolling direction, the experimental result was 0.179 $\mathrm{mm}$ smaller than the analysis result when the cutting edge was perpendicular to the rolling direction. In addition, the experimental result was $0.083 \mathrm{~mm}$ smaller than the analysis result when the cutting edge was parallel to the rolling direction.

\section{Acknowledgement}

This work was financially supported by the Frontier Mould and Die Research and Development Center from The Featured Areas Research Center Program within the framework of the Higher Education Sprout Project by the Ministry of Education (MOE) in Taiwan.

\section{Authors' contributions}

The authors' contributions are as follows: all authors conceived and designed the study; Tse-Chang Li, Kuo-Wang Liu and Dai-You Wu performed the theoretical deduction, performed the experiments and the finite element simulations, performed the process optimization and analysis; Chun-Chih Kuo and Tse-Chang Li contributed to the interpretation of the results. Kuo-Wang Liu and Dai-You Wu took the lead in writing the manuscript; Chun-Chih Kuo, Kuo-Wang Liu and Bor-Tsuen Lin contributed 
actively in writing the manuscript; all authors provided critical feedback and helped shape the research, analysis and manuscript.

\section{Funding}

This work was financially supported by the Frontier Mould and Die Research and Development Center from The Featured Areas Research Center Program within the framework of the Higher Education Sprout Project by the Ministry of Education (MOE) in Taiwan.

\section{Data availability}

The datasets generated during and/or analyzed during the current study are available from the corresponding author on reasonable request.

\section{Declarations}

\section{Ethical Approval}

The authors claim that none of the contents in this manuscript has been published or considered for publication elsewhere. Besides, the research contents of the article do not violate ethics.

\section{Consent to participate}

This manuscript does not involve human or animal participation or data, therefore consent to participate is not applicable.

\section{Consent to Publish}

This manuscript does not contain data from any individual person, therefore consent to publish is not applicable. 


\section{Competing Interests}

The authors declare no competing interests.

\section{References}

[1] Y. Liu, L. Hua, H. Mao, W. Feng, Finite element simulation of effect of part shape on forming quality in fine-blanking process, Procedia Engineering 81 (2014) 1108-1113.

[2] C. Luo, Z. Chen, K. Zhou, X. Yang, X. Zhang, A novel method to significantly decrease the die roll during fine-blanking process with verification by simulation and experiments, Journal of Materials Processing Tech. 250 (2017) 254-260.

[3] M. Krobath, T. Klünsner, W. Ecker, M. Deller, N. Leitner, S. Marsoner, Tensile stresses in fine blanking tools and their relevance to tool fracture behavior, International Journal of Machine Tools and Manufacture 126 (2018) 44-50.

[4] Q. Zheng, X. Zhuang, Z. Gao, M. Guan, Z. Ding, Y. Hong, Z. Zhao, Investigation on wear-induced edge passivation of fine-blanking punch, The International Journal of Advanced Manufacturing Technology 104 (2019) 4129-4141.

[5] H. Mao, F. Zhou, Y. Liu, L. Hua, Numerical and experimental investigation of the discontinuous dot indenter in the fine-blanking process, Journal of Manufacturing Processes 24 (2016) 90-99.

[6] G. Claus, M. Weber, D. Matthias, Increase of lifetime for fine blanking tools, Procedia Engineering 183 (2017) 45-52.

[7] Y. Liu, B. Tang, L. Hua, H. Mao, Investigation of a novel modified die design for fine-blanking process to reduce the die-roll size, Journal of Materials Processing Tech. 260 (2018) 30-37.

[8] Q. Zheng, X. Zhuang, Z. Zhao, State-of-the-art and future challenge in fineblanking technology, Production Engineering 13 (2019) 61-70. 
[9] X.H. Hu, K.S. Choi, X. Sun, S.F. Golovashchenko, Edge fracture prediction of traditional and advanced trimming processes for AA6111-T4 sheets, Journal of Manufacturing Science and Engineering 136 (2014) 021016 (11 pages).

[10] G. Huang, J. Wang, M. Hsu, K. Huang, T. Chen, T. Chen, Application of mold trough design to blanking technology, The International Journal of Advanced Manufacturing Technology 88 (2017) 1025-1034.

[11] J. Wang, A novel fine-blanking approach, The International Journal of Advanced Manufacturing Technology 78 (2015) 1015-1019.

[12] P.J. Zhao, Z.H. Chen, C.F. Dong, Experimental and numerical analysis of micromechanical damage for DP600 steel in fine-blanking process, Journal of Materials Processing Technology 236 (2016) 16-25.

[13] S. Wang, Z. Chen, C. Dong, Tearing failure of ultra-thin sheet-metal involving size effect in blanking process: Analysis based on modified GTN model, International Journal of Mechanical Sciences 133 (2017) 288-302.

[14] J. Barik, V. Sonkamble, K. Narasimhan, Burr formation and shear strain field evolution studies during sheet metal blanking, IOP Conference Series: Materials Science and Engineering 418 (2018) 012068 (8 pages).

[15] T. Tanaka, S. Hagihara, Y. Tadano, T. Inada, T. Mori, K. Fuchiwaki, Application of finite element method to analysis of ductile fracture criteria for punched cutting surfaces, Materials Transactions 54 (2013) 1697-1702.

[16] K. Osakada, K. Mori, T. Altan, P. Groche, Mechanical servo press technology for metal forming, CIRP Annals - Manufacturing Technology 60 (2011) 651-672.

[17] S. Kriechenbauer, R. Mauermann, P. Muller, Deep drawing with superimposed low-frequency vibrations on servo-screw presses, Procedia Engineering 81 (2014) 905-913.

[18] O.C. Haase, V.L. Silveira, P.M. Stemler, R.A. Viana, A.S. Duarte, Enabling 
stamping processes through meticulous FE Modelling-segmented drawbeads and remesh criteria, IOP Conference Series: Materials Science and Engineering 418 (2018) 012091 (9 pages).

[19] S. Kim, K. Tsuruoka, T. Yamamoto, Effect of forming speed in precision forging process evaluated using CAE technology and high performance servo-press machine, Procedia Engineering 81 (2014) 2415-2420.

[20] S. Olguner, A.T. Bozdana, Influence of press ram pulsation on deep drawability of dual phase steel sheet, Acta Physica Polonica A 132 (2017) 742-745.

[21] A. Fallahiarezoodar, T. Gupta, C. Goertemiller, T. Altan, Residual stresses and springback reduction in U-channel drawing of A15182-O by using a servo press and a servo hydraulic cushion, Production Engineering 13 (2019) 219-226.

[22] R. Esmaeilpour, S.A.N. Tiji, H. Kim, T. Park, H. Kim, F. Pourboghrat, B. Mohammed, Stamping of a cross-shaped part with 5052, 5754 and 6016 aluminum alloy sheets-experimental and finite element analysis comparison, IOP Conference Series: Materials Science and Engineering 521 (2019) 012002 (6 pages).

[23] S. Thipprakmas, Application of Taguchi technique to investigation of geometry and position of V-ring indenter in fine-blanking process, Materials \& Design 31 (2010) 2496-2500.

[24] S. Thipprakmas, M. Jin, M. Murakawa, An investigation of material flow analysis in fine-blanking process, Journal of Materials Processing Technology $192-193$ (2007) 237-242.

[25] T.S Kwak, Y. J Kim, W.B Bae, Finite element analysis on the effect of die clearance on shear planes in fine blanking, Journal of Materials Processing Technology 130-131 (2002) 462-468

[26] A. Kunjur, S.Krishnamurty, A robust multi-criteria optimization approach, 
Mechanism and Machine Theory, 32 (1997) 797-810. 


\section{Figures}

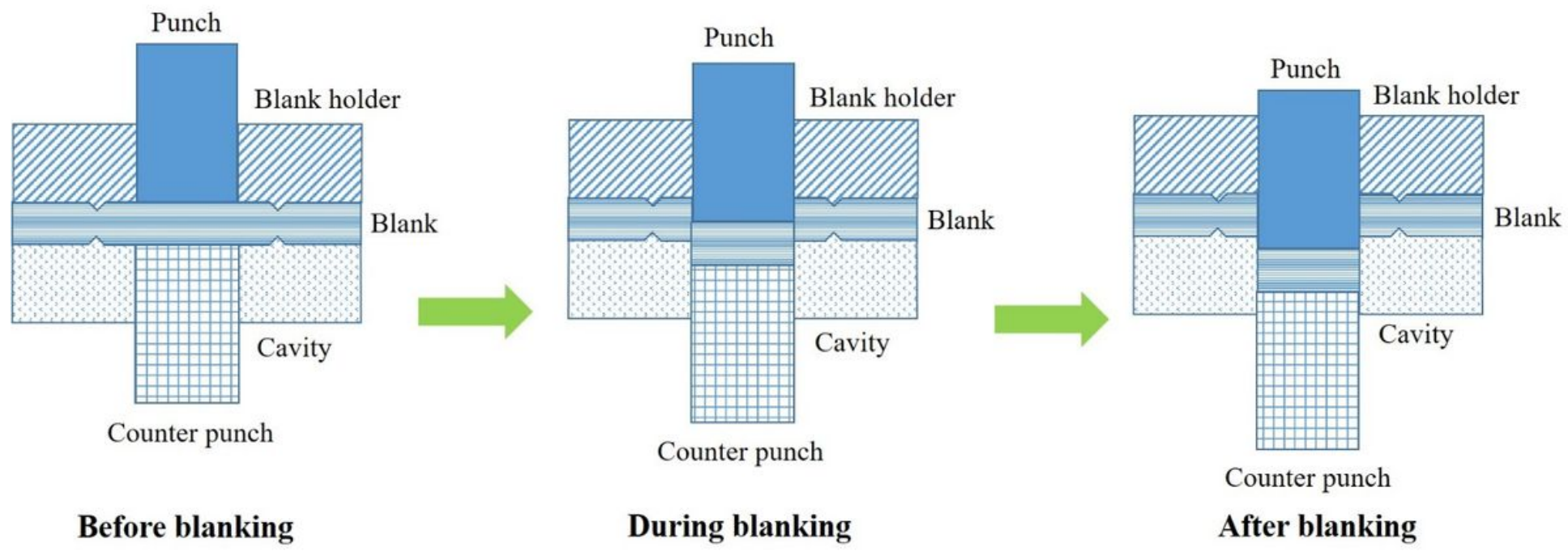

\section{Figure 1}

Fine-blanking process.

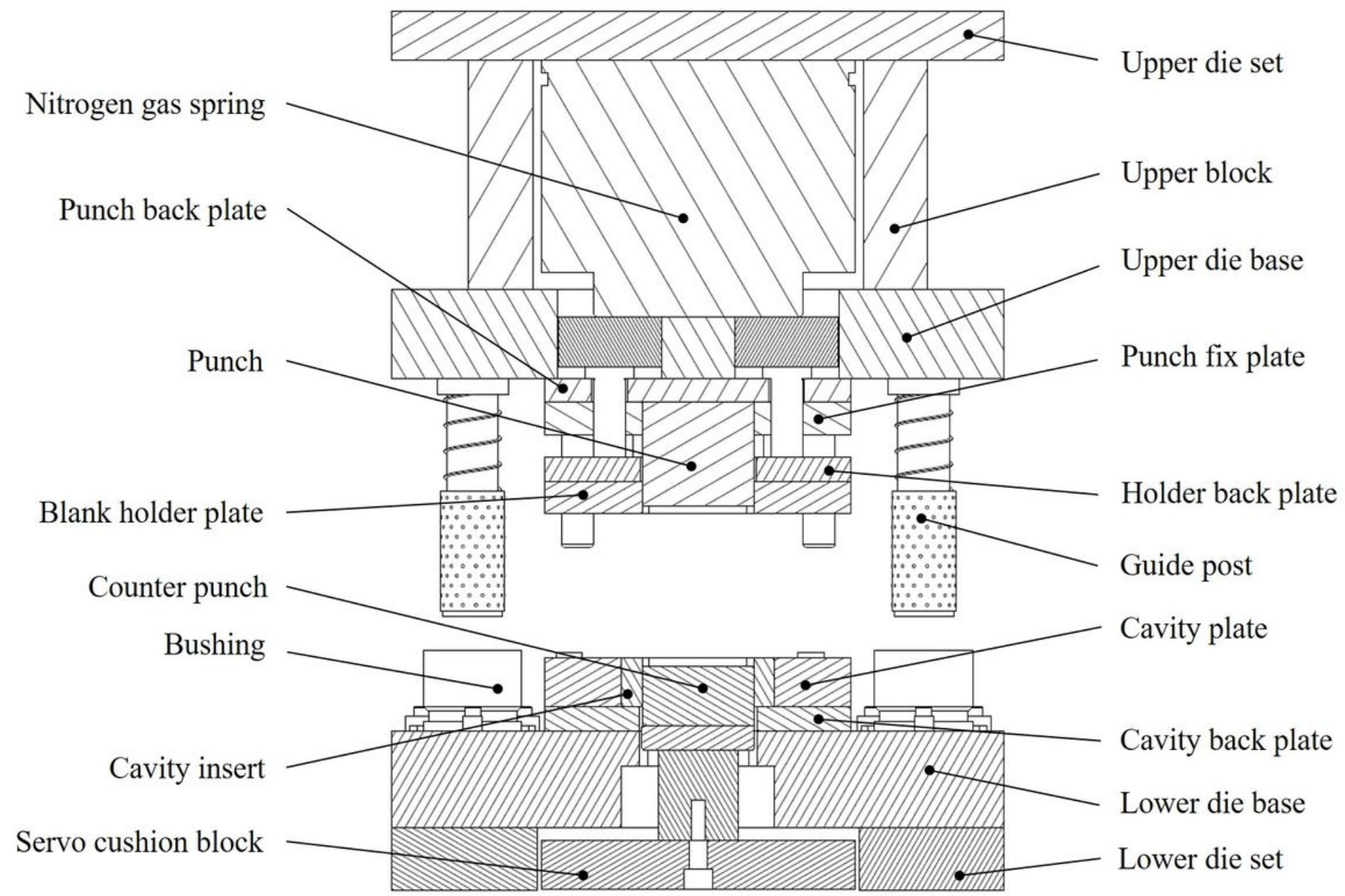

Figure 2 
Fine-blanking die.

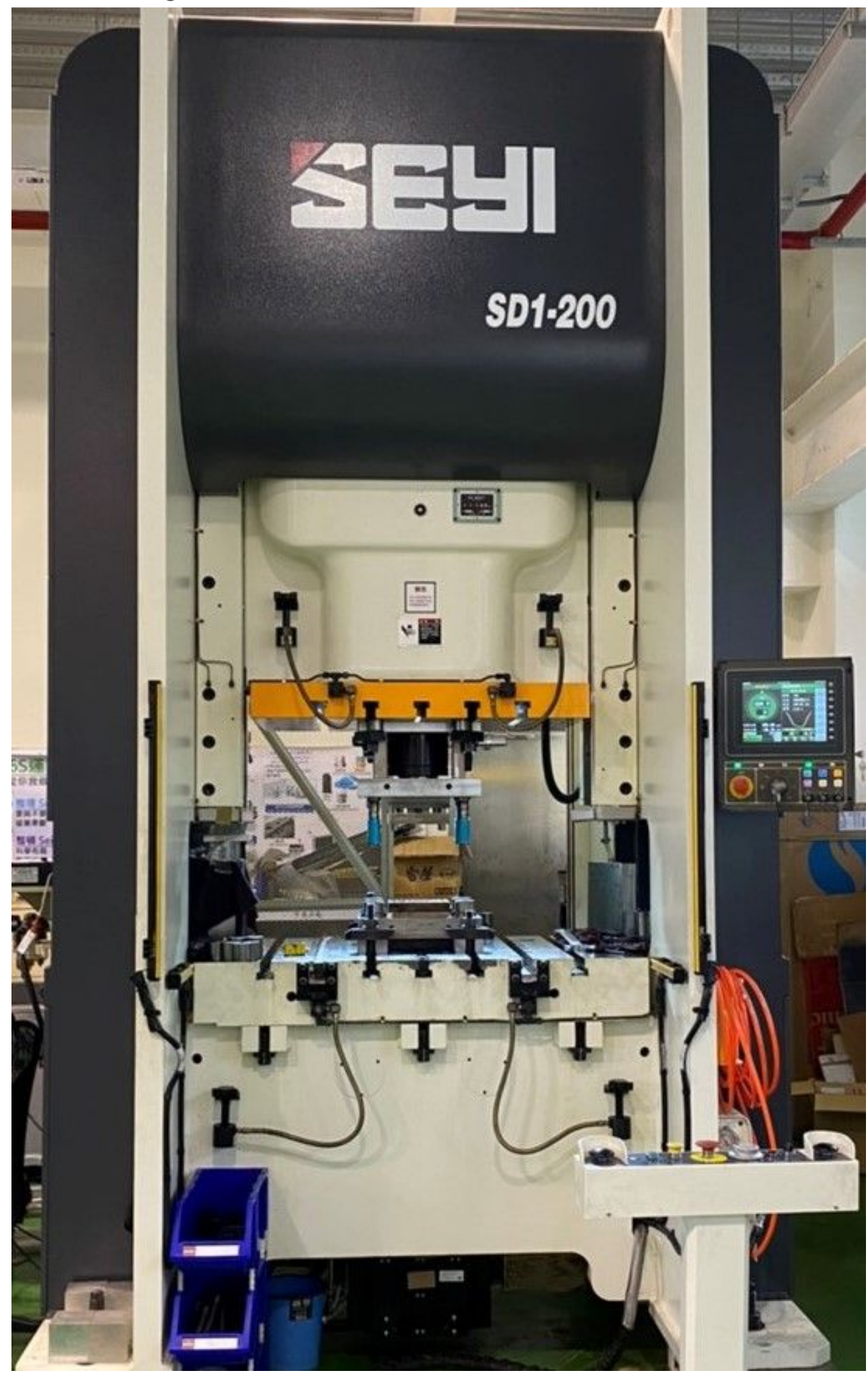

Figure 3

Servo press. 


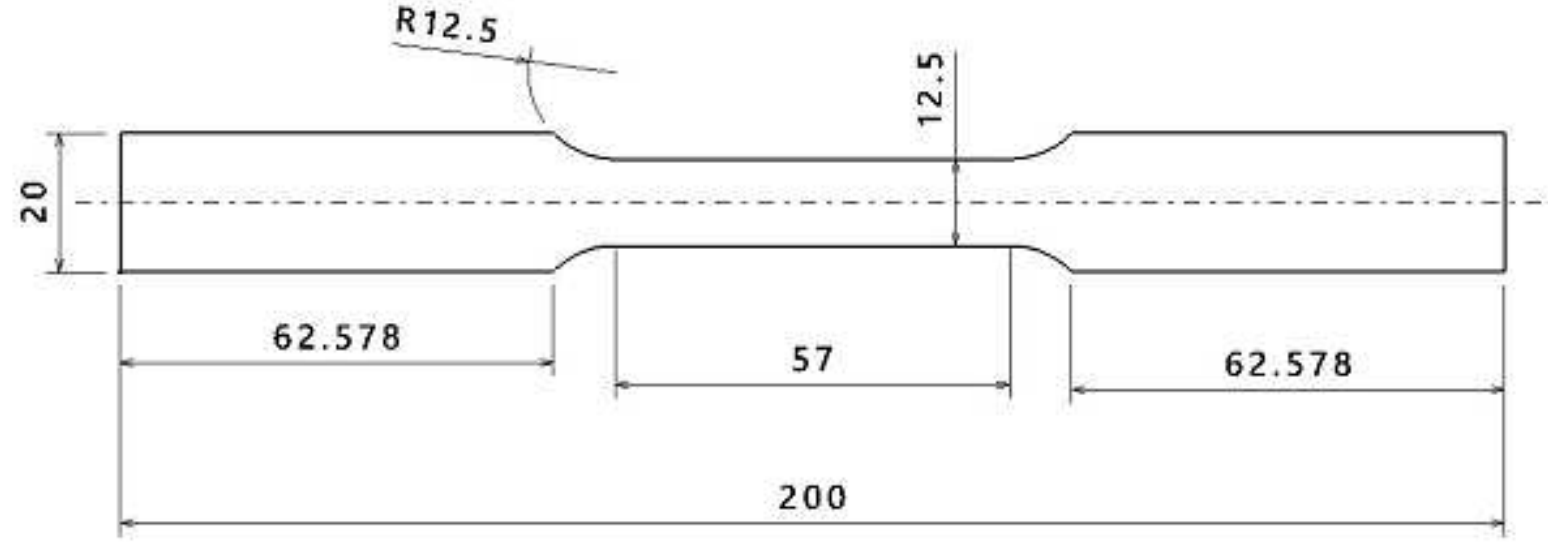

(a)
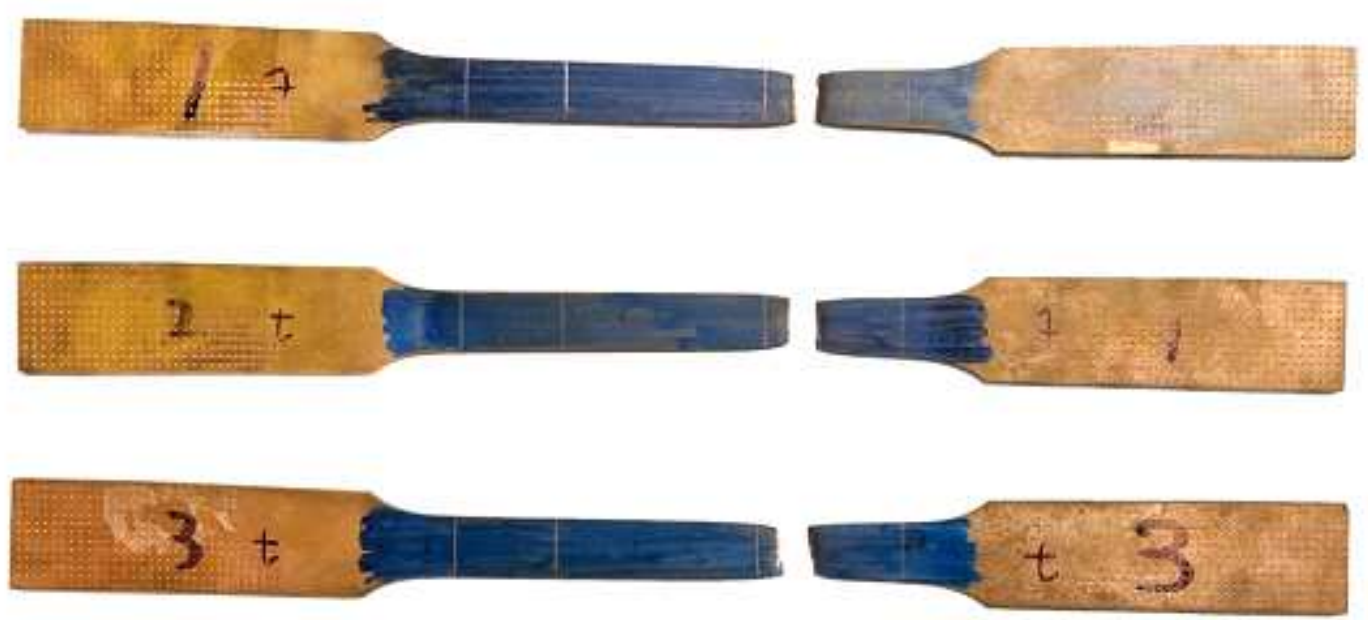

(b)

Figure 4

(a) Size of the tensile test piece; (b) the tensile test piece. 


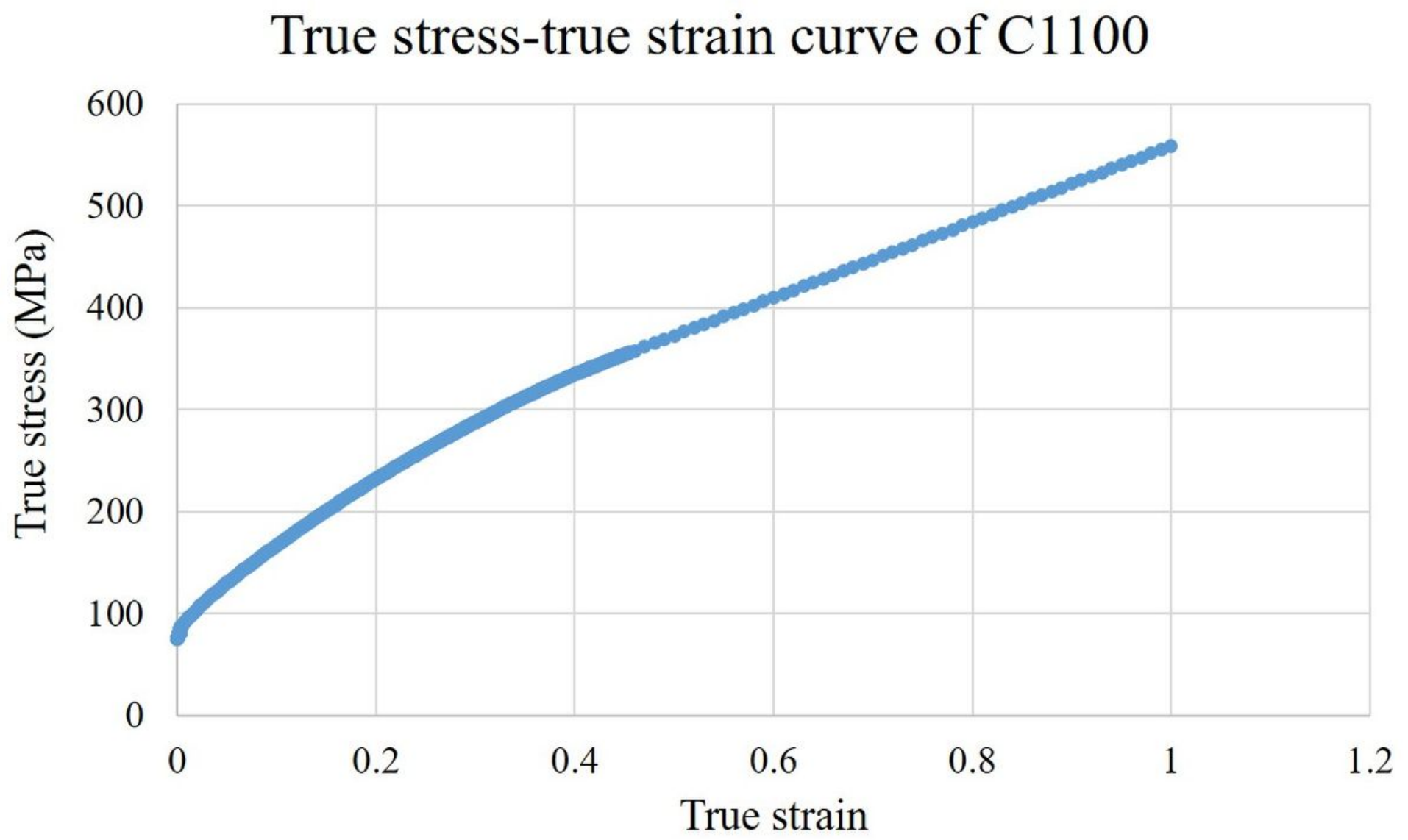

Figure 5

True stress-true strain curve of $\mathrm{C} 1100$. 


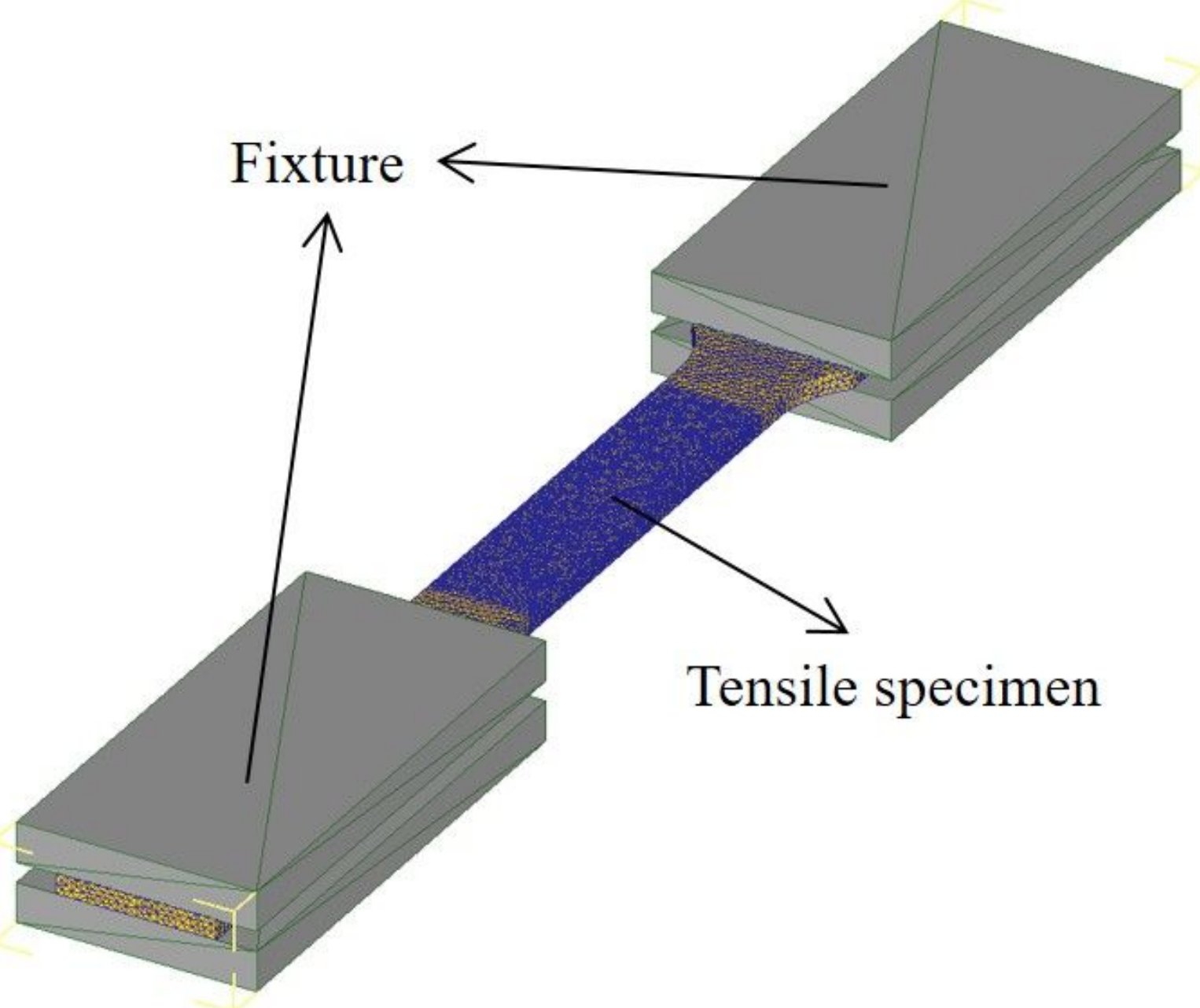

Figure 6

Analysis model of the tensile test. 


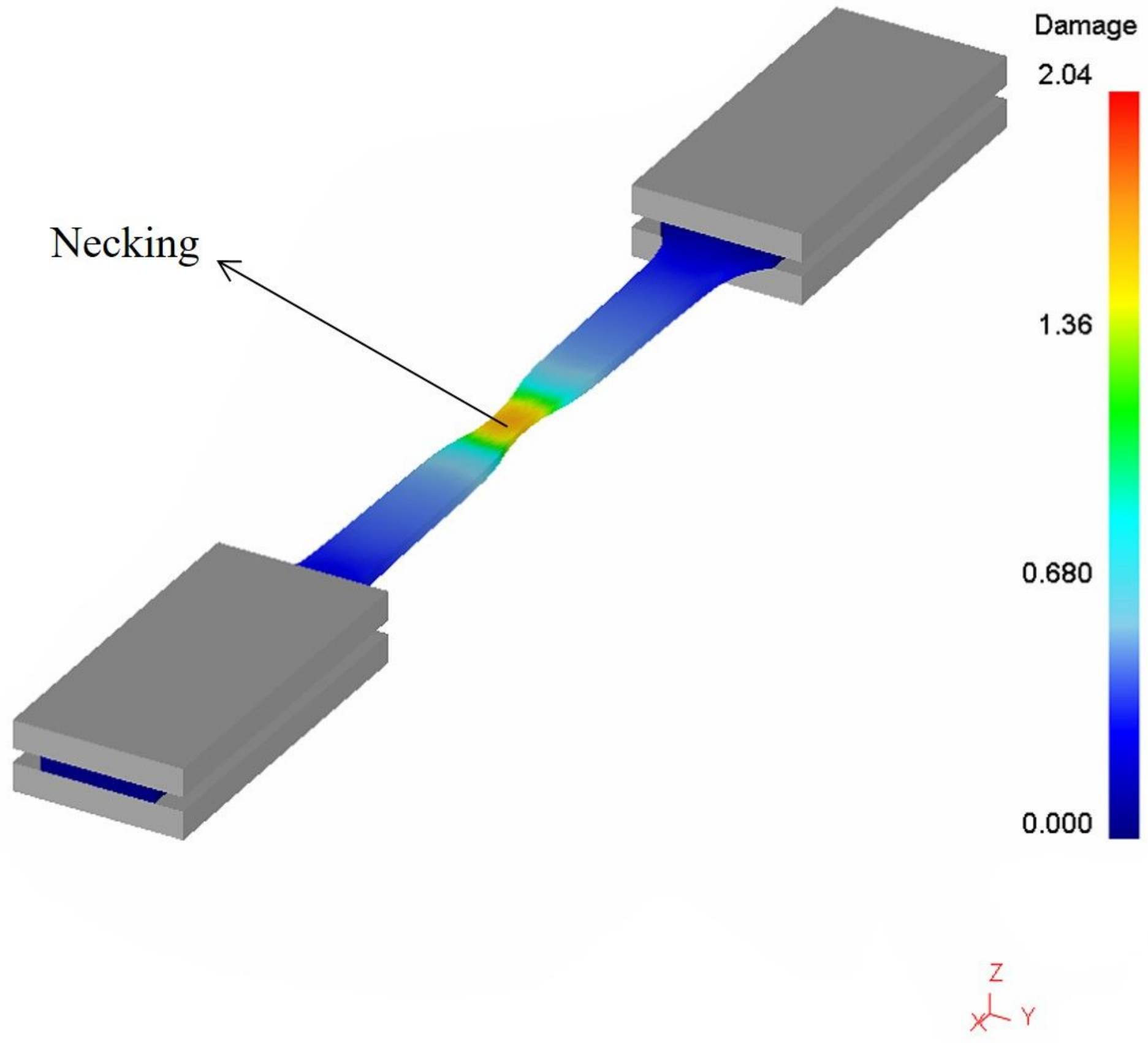

Figure 7

Simulation result of the tensile test. 


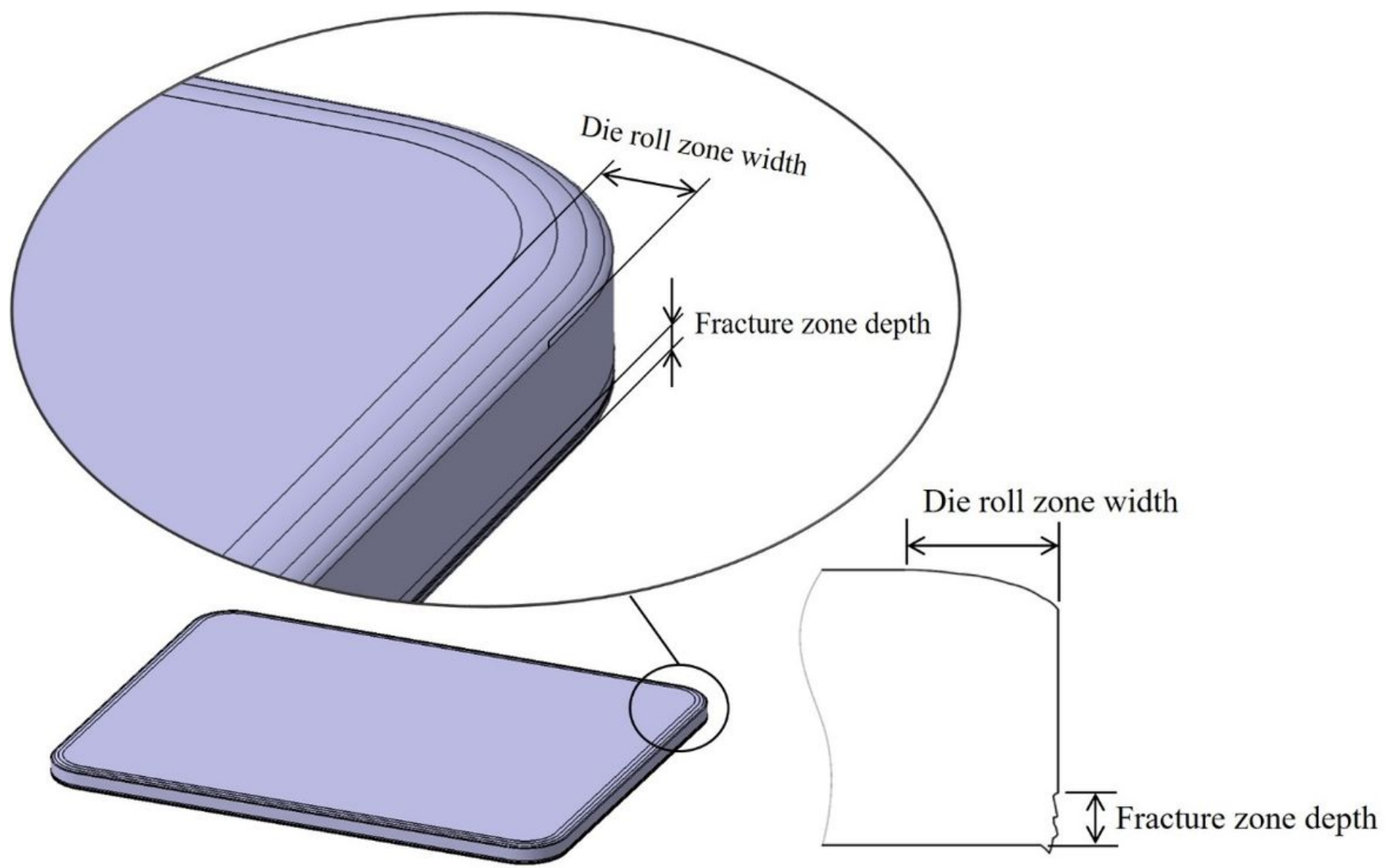

Figure 8

Fracture zone depth and die roll zone width of the CPU thermal heat spreader, which were selected as the quality objectives.

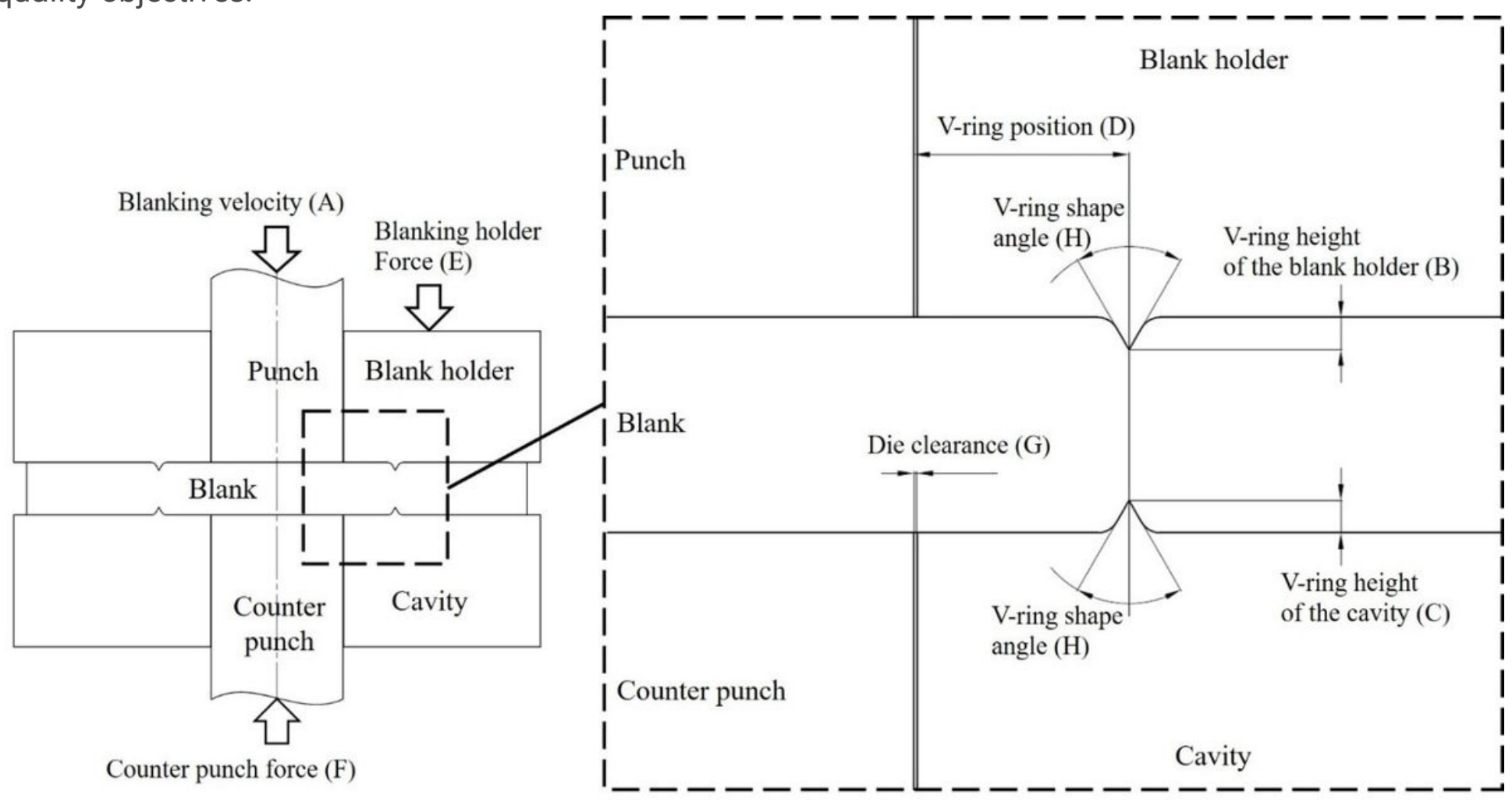


Figure 9

Fine-blanking process parameters.

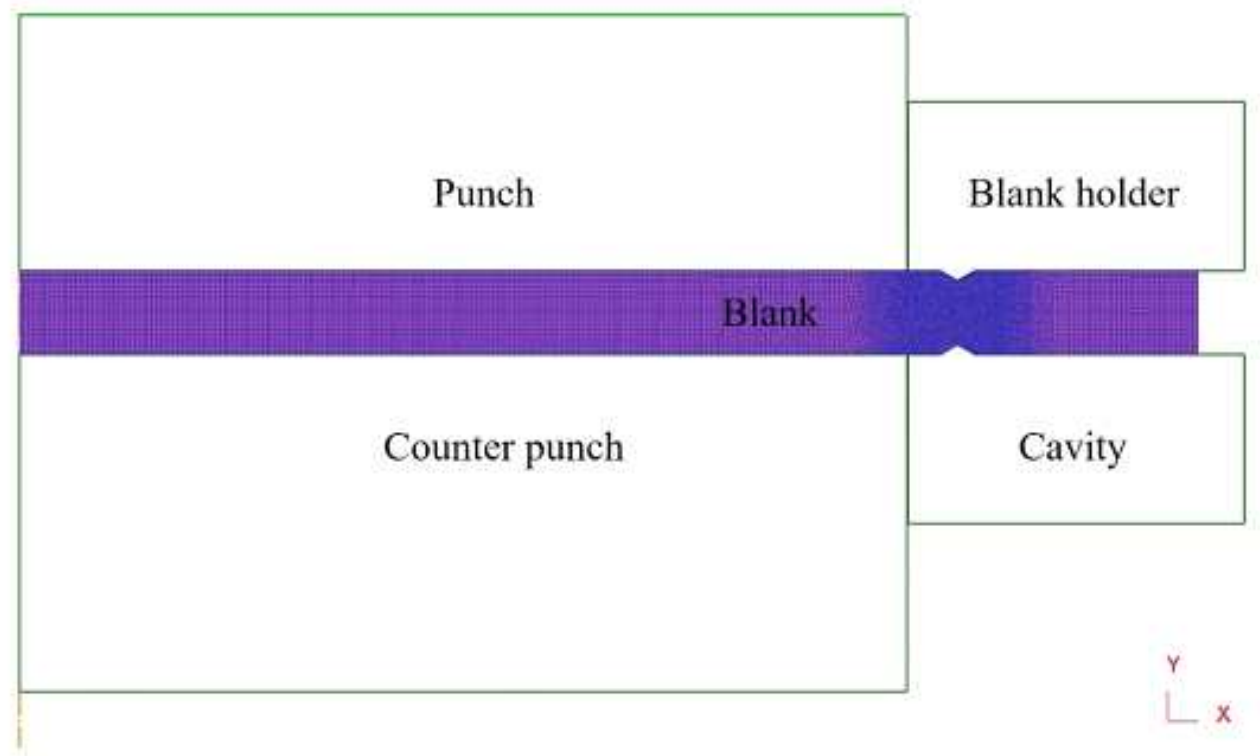

(a)

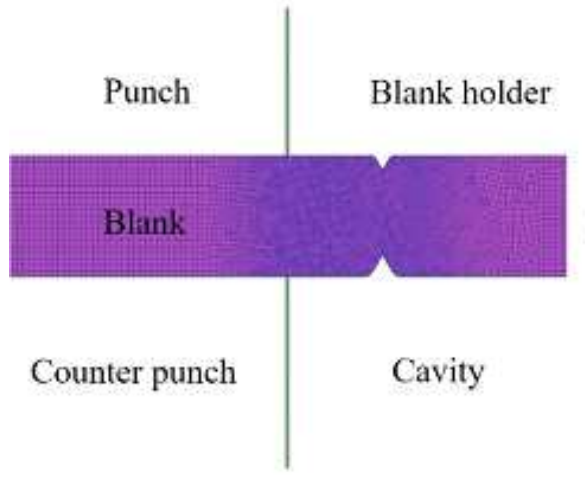

Before blanking

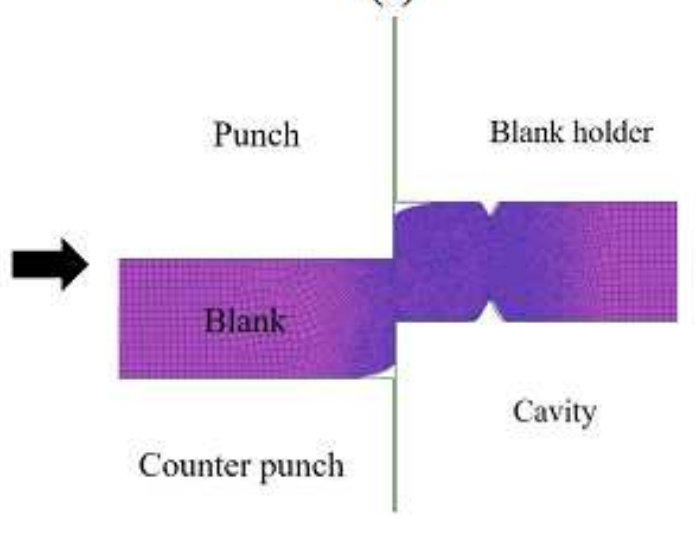

During blanking

(b)

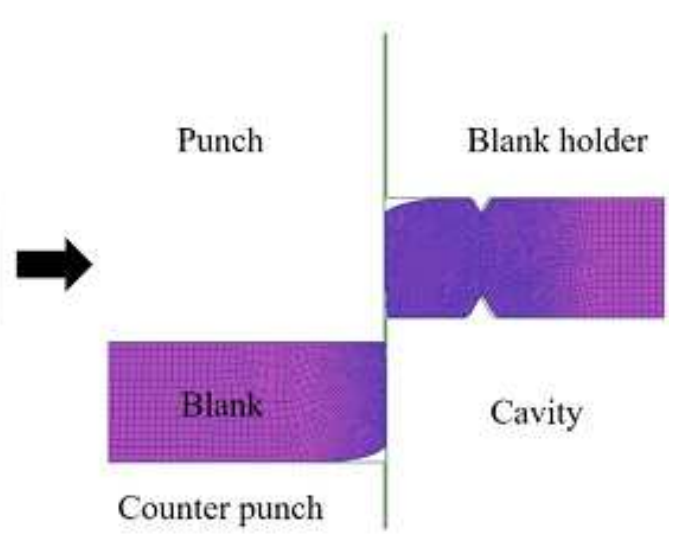

After blanking

\section{Figure 10}

(a) Analysis model of fine-blanking; (b) Fine-blanking simulation process. 


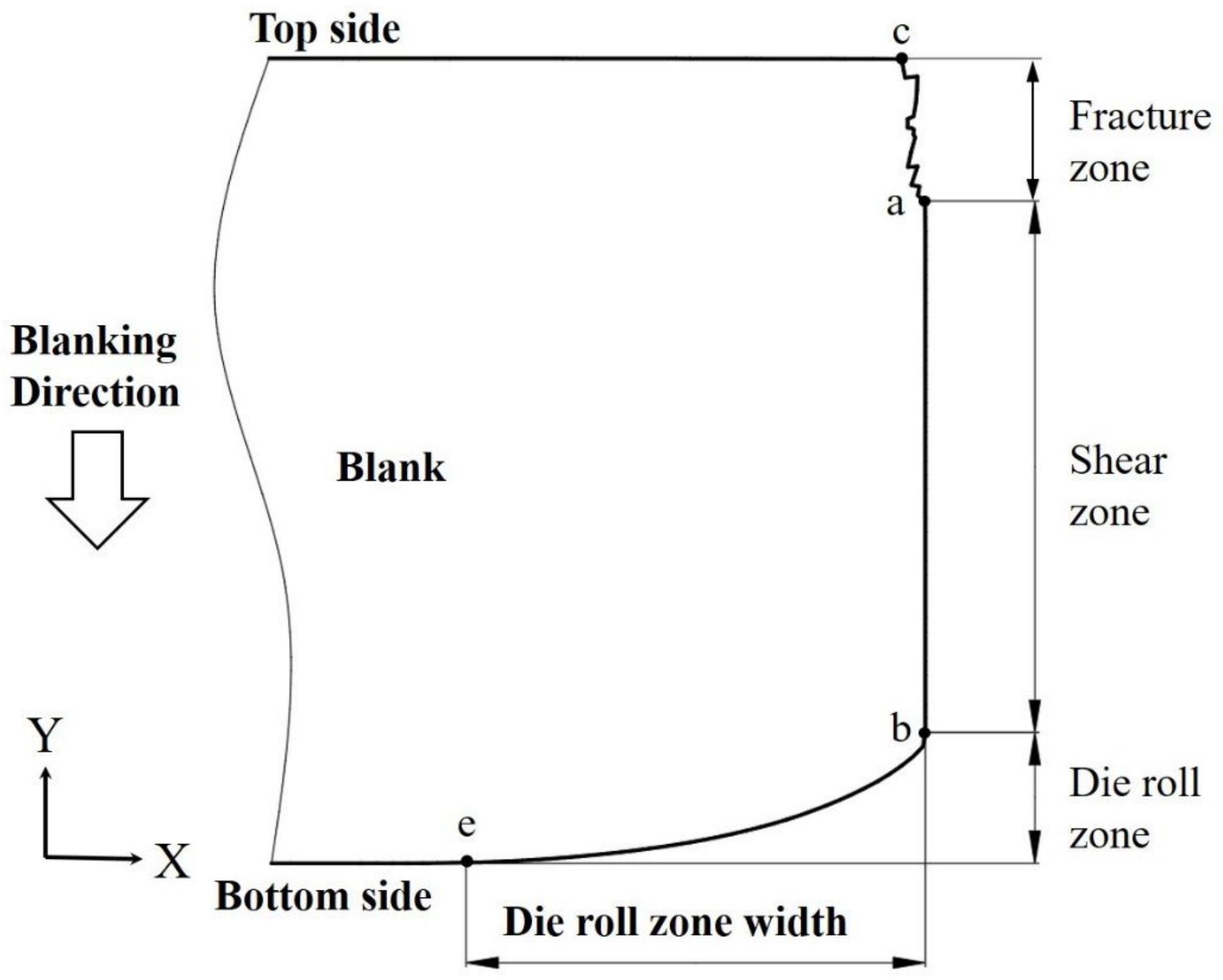

Figure 11

Defining the areas in the shear cross-section. 


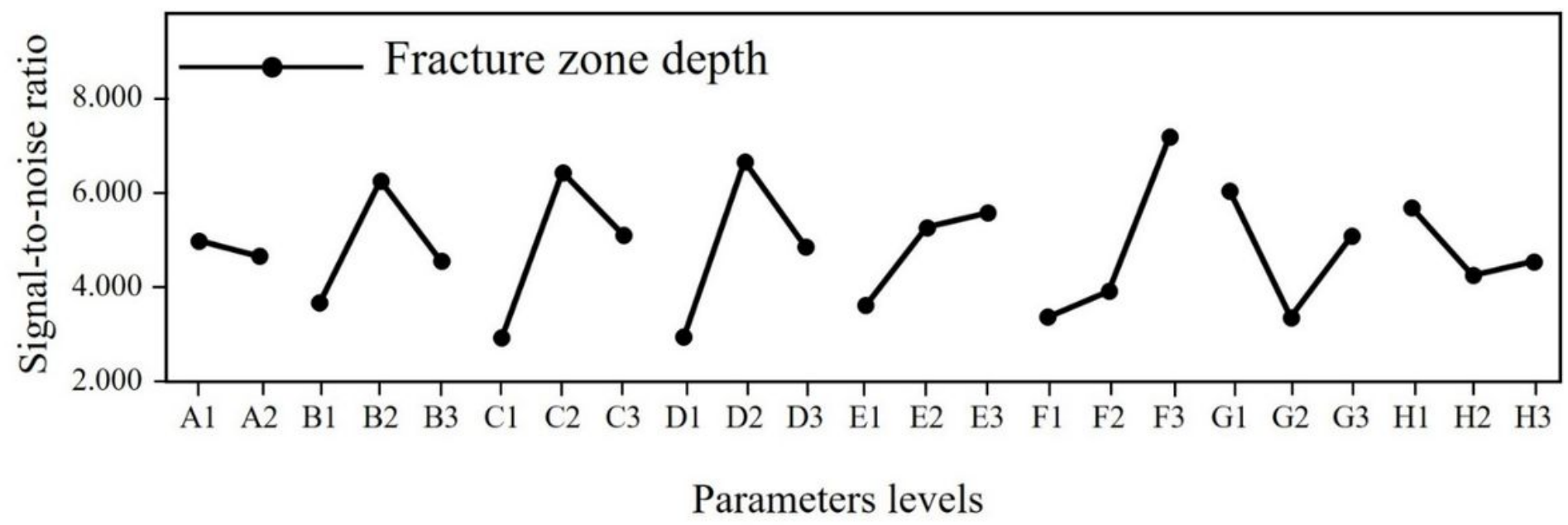

Figure 12

$\mathrm{S} / \mathrm{N}$ ratio response graph of fracture zone depth.

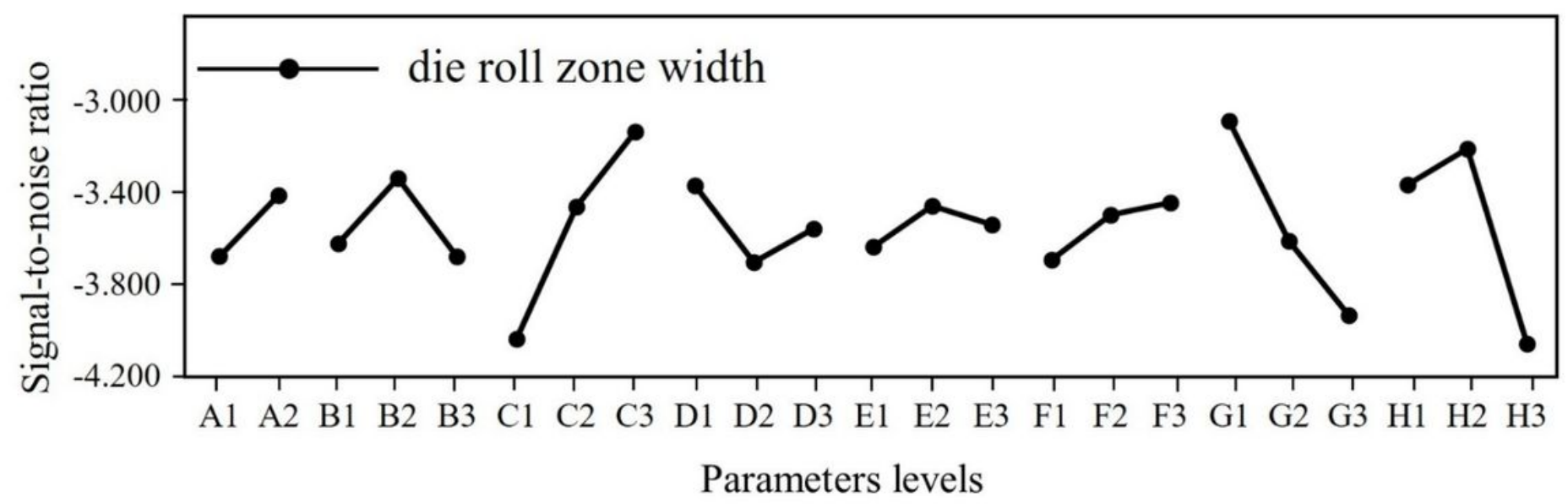

Figure 13

$\mathrm{S} / \mathrm{N}$ ratio response graph of die roll zone width 


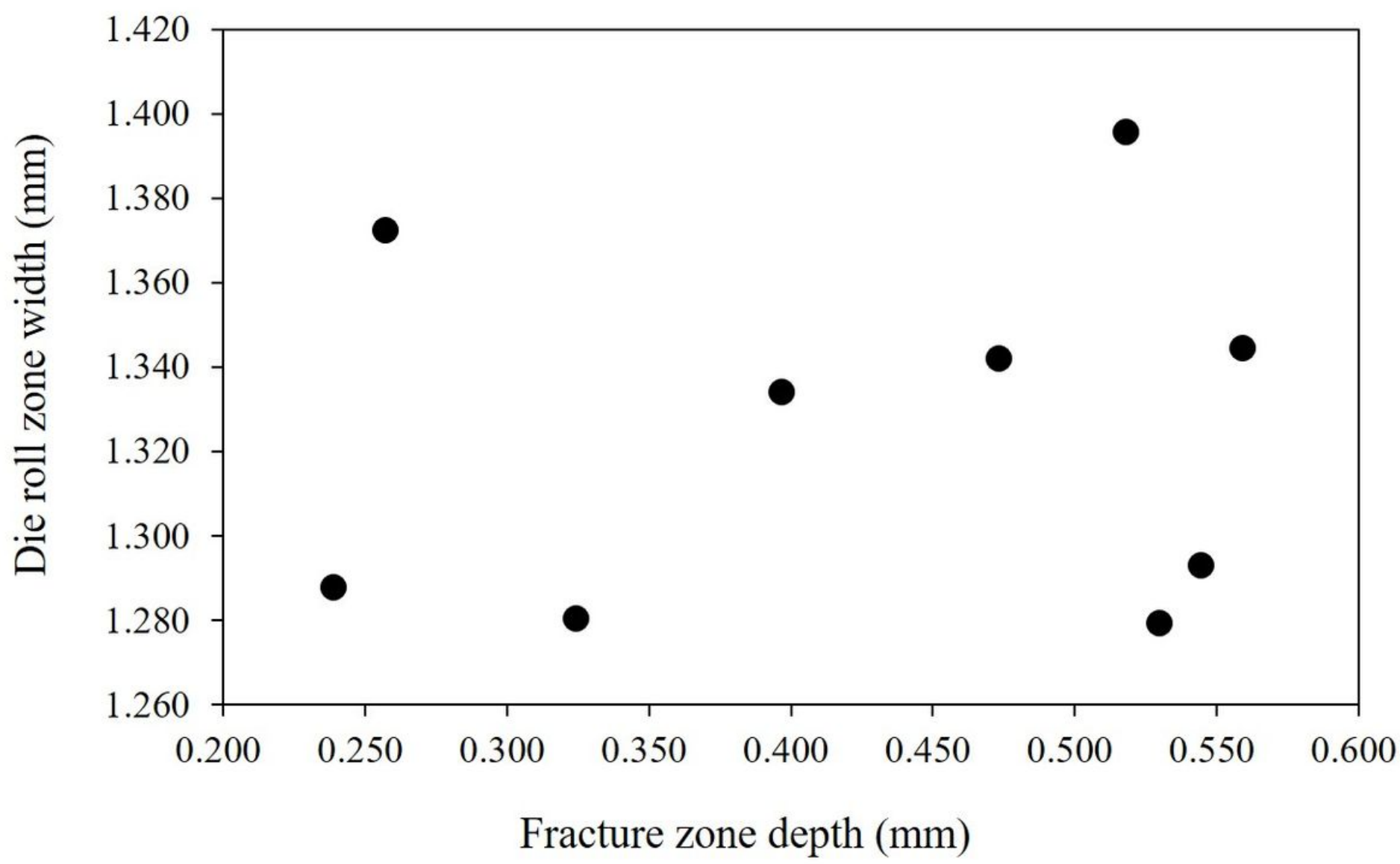

Figure 14

Pareto-optimal solutions for the fine-blanking parameters. 


\section{B Zone}

\section{Rolling Direction}

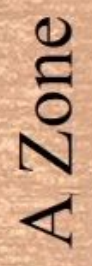

Figure 15

Measuring position of the CPU thermal heat spreader. 


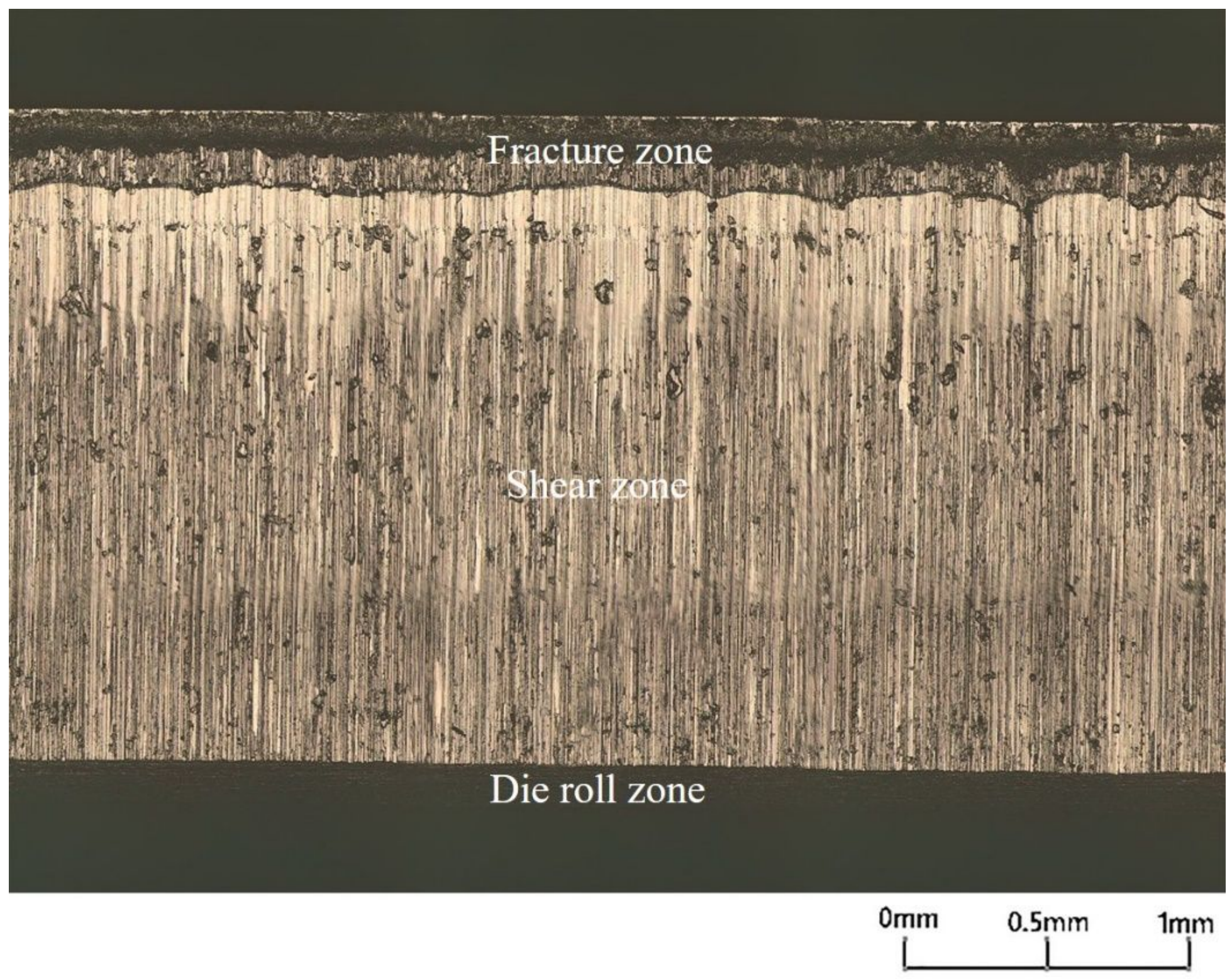

Figure 16

Shear cross-section of fine-blanking (A Zone). 